\title{
Article
}

Michael A. Boland, John M. Crespi` and Tracy M. Turner

\section{Measuring Sunk Costs in Agricultural and Food Industry Assets: Why Some Assets Sell Below Appraisal}

\begin{abstract}
Asset obsolescence or external obsolescence is a decline in the economic value of capital because of a decrease in demand for the capital's services. Measurements of sunk costs typically use appraised values of capital. In food and agricultural industries facing asset obsolescence due to government policy, appraised values may be greatly overstated and this has implications for research on industrial structure. A theoretical model to account for the appraisal error is developed and the method is applied to the U.S. sugar beet industry. The sugar beet industry displays symptoms of asset obsolescence. Our estimates indicate that plant appraisals using currently accepted practices greatly overstated the true value of these assets in 2006.
\end{abstract}

Keywords: sunk costs, obsolescence, real estate appraisal, stranded capital, sugar beet

JEL: L66, L88, Q18

DOI 10.1515/jafio-2014-0009

\section{Introduction}

As John Sutton showed in his remarkable book, Sunk Costs and Market Structure (1996), one of the key variables impacting the market structure of an industry is the size of the industry's (sunk) capital assets. While controlling for other factors, one should expect a higher level of market concentration in industries with large sunk costs, and Sutton shows that across many industries this is an

*Corresponding author: John M. Crespi, Department of Agricultural Economics, Kansas State University, 342 Waters Hall, Manhattan, KS 66506, USA, E-mail: jcrespi@agecon.ksu.edu

Michael A. Boland, Department of Applied Economics, The Food Industry Center, University of Minnesota, 317B Ruttan Hall, 1994 Buford Avenue, St. Paul, MN 55108, USA, E-mail: boland@umn.edu Tracy M. Turner, Department of Economics, Kansas State University, 327 Waters Hall, Manhattan, KS, USA, E-mail: turner@ksu.edu empirical regularity. Like all costs, sunk costs are difficult to measure. The sunk cost measure proposed by Sutton and used in several studies of industry market structure is the ratio of the gross book value of depreciable assets to the total value of shipments. For example, Schulz and Crespi (2012) examined the relationship of this variable to the Herfindahl-Hirschman Index (HHI) for 44 food manufacturing industries in the United State from 1997 to 2007 finding a $1 \%$ increase in this asset/value ratio significantly increased the average $\mathrm{HHI}$ in food manufacturing industries by half a percent.

As Sutton shows, the evidence that this variable is important in research on industry structure is well documented. One must always be cautious using variables collected from bookkeeping as proxies for economic costs, especially values that involve depreciation (Fisher and McGowan 1983). In some industries, knowledge of the value of depreciable assets is quite straightforward. A tractor-trailer or automated assembly line have wellunderstood secondary markets making their depreciation forthright. Relatedly, many industries have more certainty about future demand for their goods. Automobile design may change, but personal transportation is not likely to go away anytime soon. In such industries, asset appraisal is straightforward. This is not always the case in food and agricultural industries especially when government policy impacts the relative profitability of a firm in that industry.

What is the value of a fishing boat if next year the United States and Canada agree to limit fishing in the North Atlantic but not the North Pacific? What happens to a sawmill's worth if Spotted Owls decide to nest nearby? What happens to ethanol plants if government subsidies and fuel requirements change? All industries face risk to their survival, but an argument could be made that food and agricultural industries are particularly sensitive to such risks because of their reliance in some cases on a great deal of governmental largesse. Further, although assets undergo appraisals by outside real estate experts, there are aspects of risk in agriculture 
that are difficult to measure using extant appraisal methods that nevertheless impact the future viability of the assets. Put simply, a new Farm Bill can greatly change the appraisal of an asset if it greatly changes the viability of a food manufacturing industry. But, such risk may not have been well understood when the asset was purchased. In food and agricultural industries with greater than typical sensitivities to regulations and policy changes, accuracy in appraised values is even more essential to the efficient operating of the real estate and capital markets of these industries and, in turn, the understanding of the impacts on their industrial structure.

Because some food and agricultural industries are dependent upon underlying governmental policies, appraisal methods based mostly on historical asset prices (the current method), often miss the underlying riskiness of these assets and hence the underlying riskiness of the industry. United States sugar beet plants offer an example. When sold, plants have often sold for fractions of their appraised values meaning that the book value of the assets was greatly overstated. Currently accepted asset appraisal methods fail to take into account a form of economic obsolescence due to the uncertainty of the potential economic impacts as well as the fact that markets for certain types of property may be thin in rural regions, making sales comparisons difficult. Accurately measuring the uncertainty of economic impacts due to potential obsolescence is hampered by government programs that are directly linked to the profitability of an agribusiness.

Industries that benefit from trade protection or are at risk of obsolescence due to government regulations include lumber milling (e.g., the event of an endangered species discovery), fish processing (e.g., asset values are impacted by government regulations on fisheries), and corn-based ethanol production (e.g., profitability dictated by presence of an ethanol mandate). Furthermore, as will be seen in this article, industries such as sugar beet processing, by virtue of their geographic concentration and scale of industrial investment, have no alternative use if the government program on sugar expires. In particular, we are interested in what might be better termed "external obsolescence" or "unplanned economic obsolescence," defined as a decline in the economic value of capital because of a decrease in demand for the capital's services, and, in our application, that could be arising from a change in government policy. ${ }^{1}$ We see three

1 This definition is taken from footnote 2 of Troxel $(1936,267)$ and is used by the United Nations, Commission of the European Communities, the International Monetary Fund, and the Organization for Economic Cooperation and Development. This definition differs from the usage of avenues adding to the current research stemming from this paper.

One objective of this research is to develop a method based upon an accepted economic theory of depreciation for estimating potential obsolescence in the context of appraisals and asset profitability. By doing so, we provide a general formulation for "correcting" Sutton's measure of sunk cost if an industry is believed to be particularly vulnerable to the type of economic obsolescence we have been describing.

A second objective is to provide an example of the technique by applying it to the U.S. sugar beet industry. This industry is chosen because it is an excellent candidate for exactly the type of asset overvaluation we have described. More so than in other industries, government sugar policies substantially impact the profitability of the industry.

The third objective is the potential for providing another estimation technique for what is termed in the resources literature "stranded capital." When there is an unforeseen decrease in demand for the capital's services, the capital becomes "stranded." The U.S. Environmental Protection Agency (2011) defines stranded capital as, "The abandoned equipment costs, either as new, or at reduced value when replaced after a prematurely truncated period of time in production" (U.S. Environmental Protection Agency 2011). The key phrase is "prematurely truncated" since a foreseen decline in the capital's value (e.g., traditional sunk costs) can be accounted for in a firm's asset appraisal through traditional depreciation. A firm facing the potential for stranded capital puts its asset valuation at risk since the stranded capital occurs due to unforeseen and potentially sudden depreciation (Wilen 2009).

\section{Appraisal literature}

The literature on appraisal techniques is lengthy with considerable investigation devoted to whether appraisals adequately capture true market values. Research examining the impact of government programs on market values either directly or via capitalization in property values has also been studied. The intersection of these two research questions, however, has not been studied. The theory of how appraisals should reflect capitalized values is

economic obsolescence in the industrial organization literature in which a firm purposely degrades the durability of its product so as to have repeat purchases more quickly. 
discussed in Netzell (2009) but most studies of problems of appraisal methodology concern the extent to which reported sales transactions relate to the appraisals on those properties. Most studies of appraisal bias seek empirical tests of moral hazard theory or perform inductive analyses to better inform a theory (i.e., Stevenson, Young, and Gurdgiev 2010).

Most studies use regression analyses based upon a model of capitalization where capitalization rates, rental rates, or property values are regressed on various factors including some aspect of governmental policy. In other words, a reduced-form or hedonic regression approach is used to measure the impact of policy on property values. Oates (1969) was one of the first studies of property tax capitalization into property values followed by a number of articles on this topic. A non-exhaustive example of the literature on how property values are affected by federal income tax policies includes Fisher, Lentz, and Stern (1984), Nourse (1987), Hilber and Mayer (2009), Hilber and Turner (2013).

With regard to agriculture and natural resources, Featherstone and Baker (1988), Barnard et al. (1997) and Kirwan (2009) examined the extent to which federal farm programs increased farmland values. Jackson (2001) summarized much of the early literature on how environmental damage affects real estate prices. Tyrvainen and Miettinen (2000) examined property values in relation to the presence of government managed forestland. The relationship between appraised and actual values in thin markets and the presence of obsolescence due to agricultural policy has not been studied.

\section{Development of a theoretical model}

A review of AgEcon Search, JSTOR and Google Scholar find more than 100 articles written by agricultural economists on asset replacement and depreciation but none examine specifically the poor performance of the appraisal in valuing an agricultural asset. Kolbe and Borucki (1998) is the only model of which we are aware that develops an empirical application from a theoretical model of economic obsolescence. The literature on asset valuation and depreciation has its roots in Hotelling's (1925) seminal paper but he did not provide guidance on how to estimate the potential for obsolescence from policy changes.

The simple explanation for why an agricultural asset sells for less than book value is that the appraiser simply ignored some underlying industry risk that an entrepreneur buyer exploited. That knowledgeable appraisers would consistently miss this seems odd, however. A theory is needed that incorporates the potential from a loss in utility of the asset and allows a measurement of the difference between the appraisal and the asset's contribution to profitability. The key issue, we believe, from the perspective of an asset appraisal, is not simply the relationship between profit and risk, but rather determining the optimal time to sell a depreciating asset as noted by Burt (1972) and Perrin (1972).

An appraiser makes an assumption based upon sales of similar assets without considering the timing of those sales and that assets sold after some period may be in an entirely different market than the one operating previously. The important piece of information, then, is whether the asset one is appraising is on the upward or downward portion of an optimization where the choice is when to sell the plant. In agricultural asset appraising, no such consideration that we are aware of is made. But, in industries such as lumber milling, fisheries, sugar beets, coal mining, or ethanol, it is crucial. Once the theory is developed, we can determine empirically whether an asset is past its prime sales date given the risk of industry changes and, if so, then we should expect standard appraisals to underestimate its value.

Based on the present value approach of Hotelling (1925), we frame our model of the impacts of obsolescence on valuation as Hotelling did by asking, when is the optimal time to sell a depreciating asset? At time $t$, the net income generated by an asset (such as a sugar beet plant or sawmill) is equal to

$$
\pi(t)=p(t) Y(t)-C(t)
$$

where $p(t)$ is the price per unit of the manufactured good, $Y(t)$ is the quantity produced, and $C(t)$ is total operating expenses. External obsolescence is related to economic efficiency (e.g. Fare, Grosskopf, and Lovell 1985), so we next adopt the convention of the efficiency literature by binding our measure of the inherent risk to the industry from government changes and other conditions in the function $\theta(t) \in[0,1]$. Doing so allows an interpretation of external obsolescence as a probability, making the following treatment consistent with more well-known interpretations of risk where uncertain government programs implicate expected returns (e.g., Moschini and Hennessy 2001). In the model, as the potential for plant/industry obsolescence from these outside forces increases, then $\theta(t)$ to approaches zero. When $\theta(t)=0$, the asset is economically obsolete and earns a negative rate of return, and when $\theta(t)=1$, the asset is fully competitive and earns a 
positive rate of return equivalent to the discount rate; thus $1-\theta(t)$ may be viewed as the amount of measurable external obsolescence impacting the asset. ${ }^{2}$

This type of asset or external obsolescence is a function of time but in a way exogenous to the firm because it comes about through market forces affecting net returns as noted by Hotelling, and those market impacts will vary from one period to the next. Costs from usage of potentially obsolete inputs and revenues from exogenous factors that affect demand for the output would be affected by $\theta(t)$ but precisely how those variables are affected is less certain. As such, we assert a firm's net income flow at time $t$ is hampered by this risk in a scaled manner through revenues or costs or both, namely the real net income can be assumed $\theta(t) \pi(t)$.

The value of the property's assets, likewise a function of this potential for obsolescence, is given by $S(\theta(n))$ if the asset is sold at time $t=n$ with perfect foresight, namely, the time that the sales value is maximized. Using Hotelling's continuous time notation, the present discounted value of the stream of income plus the sales value at time $n$ is:

$$
V(t)=\int_{t}^{n} \theta(\tau) \pi(\tau) e^{-\int_{t}^{\tau} \delta(v) d v} d \tau+S(\theta(n)) e^{-\int_{t}^{n} \delta(v) d v},
$$

where $\delta(t)$ is the discount rate, and we want to know what is the maximum value of eq. [2] if the asset were to be liquidated at time $t=n ?^{3}$

$$
\begin{aligned}
\left.\frac{d V(t)}{d t}\right|_{n}= & \theta(n) \pi(n) e^{-\int_{t}^{n} \delta(n) d n}+S^{\prime}(\theta(n)) \theta^{\prime}(n) e^{-\int_{t}^{n} \delta(n) d n} . \\
& -\delta(n) S(\theta(n)) e^{-\int_{t}^{n} \delta(n) d n}=0
\end{aligned} .
$$

Rearranging eq. [3] gives:

2 Bounding the measure of obsolescence between zero and one in no way bounds returns, which can be positive or negative. One could relax the bounding assumption and allow for the case where very large external shocks could make the obsolescence term less than or greater than our bounds. Theoretically, an appraiser with perfect information would accurately predict the true value of the assets taking the shock into account and as such the bound represents a formalization of any number line used to relate realized economic profits into the appraisal of the asset.

3 If $t>0$ then $V(t)$ is the discounted value of the future stream of returns. If $t<0$ then $V(t)$ is the value at time $t$ of a stream of past returns (a current or future value). Throughout the text, we use the less confusing language considering the future stream of returns $(t>0)$. Noting $t$ may be positive or negative generalizes the formulation so that one could discern not only the optimal point in the future to divest but also whether an asset should have already been sold (see Hotelling 1925, footnote 1).

$$
\pi(n)=\frac{\delta(n) S(\theta(n))-S^{\prime}(\theta(n)) \theta^{\prime}(n)}{\theta(n)} .
$$

Eq. [4] is an implicit function of the optimal selling date, $n .{ }^{4}$ It is important to understand the distinction between $n$ and $t . n$ is a specific time derived from the optimization of eq. [2]. If the asset is still utilized at $t>n$, it means that the asset's owners did not sell at the optimal time. Likewise, economic factors can change the value of $n$ at any time $t$ and those factors can affect the owners' choice on the optimal time to sell. For example, unexpected changes in government policy adverse to an industry's profitability can decrease the value of $n$ whereas pro-industry policies would increase it. Likewise, an owner who has a very optimistic forecast that policy might in the future affect an industry's viability, might choose to ignore an appraiser's estimate of the optimal time to sell the asset. The optimal time to sell an asset might be in the future, but it might also have already occurred. A value of $n$ equal to -5 means that the asset ought to have been sold 5 years ago to maximize the net present value of the investment. As $\theta(n)$ approaches zero in eq. [4], the property becomes increasingly obsolete but the theoretical effect on net returns is not clear.

In order to use eq. [4] to derive estimates of economic obsolescence and the divergence between appraised value and market value, we build on Hotelling's model and parameterize the economic obsolescence term, $\theta(n)$, and the sales value function, $S(\theta(n))$. The optimal time to sell the asset will necessarily depend upon a number of exogenous factors beyond the time dimension of asset depreciation suggesting that the optimal time to sell can be parameterized. Needing a function to hold our obsolescence term between 0 and 1 , we simply model economic obsolescence using a logistic distribution ${ }^{5}$ :

$$
\theta(n) \equiv \frac{e^{n}}{1+e^{n}} .
$$

4 Eq. [4] is equivalent to Hotelling's (1925) eq. [3] written with the output price on the left-hand side. Using our notation, with $\theta(t)$ relegated to a cost of operation gives Hotelling's eq. [3]: $p(t)=\left[C(t)+\delta(t) S(t)-S^{\prime}(t)\right] / Y(t)$.

5 The logistic distribution was chosen because its mathematical properties allow simplification in the nonlinear model that follows but also because this function allows for variables that would both positively and negatively impact obsolescence. We also tested the distribution, $\left.\theta(t)\right|_{n} \equiv e^{-n^{2} / 2}$, which has been used in duration analyses. This distribution results in a different estimating equation but both estimations gave similar measures of the calculated obsolescence. Any CDF ought to work in this construction. 
Following the earlier discussion, although at first glance it may appear odd that obsolescence increases in $n$, recall that $n$ differs from $t$ in that $n$ is the result of the solution of eq. [3]. While it is true that normal depreciation over time pulls down the value of all assets, we are not modeling that depreciation. The external obsolescence, which $\theta(n)$ measures, shows the viability of the asset due to external factors. The logistic distribution gives us what we expect, namely, a larger $n$ means that the optimal time to sell is farther in the future and a smaller $n$ means the optimal time to sell is nearer or, even, when $n<0$, in the past. In the extreme, if $n$ goes to infinity we conclude the industry is expected to be vibrant for a long, long time. If $n$ is negative, it means that the optimal time to sell has already passed the owners by. Thus in the other extreme, as $n$ goes to negative infinity, $\theta(n)$ goes to zero because the assets are economically obsolete. In Amish regions of the United States, the assets in horsedrawn carriage factories may still have a large $n$ while, in contrast, carriage factories elsewhere trying to compete with auto makers should have sold out a long time ago. For some U.S. food manufacturers and the farmers who supply them, certain government policies may make $n$ large while a change to those policies may turn $n$ negative with the next farm bill.

While $n$ is the choice a firm makes, $x_{t}$ is a vector of market factors exogenous to the industry such that $n=n$ $\left(x_{t}\right)$. If these exogenous factors increase economic obsolescence, then they would have a negative effect on net returns and asset value, whereas factors that increase an industry's viability would have positive effects. We should expect the optimal $n$ to be impacted differently by these factors from year to year, in other words.

One way to consider the salvage term is by assuming that sales value is a simple proportion of $A_{t}$, the appraised value of a plant at time $t$, and that plant's economic obsolescence. Specifying the sales value at time $t=n$ as

$$
S(\theta(n))=A_{n} \theta(n)
$$

allows us to readily express the returns on the asset as a function of economic obsolescence, itself expressed as a fraction. Thus, the economic salvage value dampens the appraised book value by the extent of obsolescence and the rate of change of this salvage value is just the change in the appraised value so that $S^{\prime}(\theta(n))$ is equal to $A_{n}$. Since the derivative of the logistic function with respect to $n$ yields

$$
\theta^{\prime}(n)=\theta(n)[1-\theta(n)]
$$

then substituting these expressions into eq. [4] yields

$$
\pi(n)=\frac{\delta(n) A_{n} \theta(n)-A_{n} \theta(n)[1-\theta(n)]}{\theta(n)} .
$$

Simplifying this expression and then dividing by the appraisal allows us to express eq. [8] in a useful manner as a simple net return on the appraised asset

$$
\frac{\pi(n)}{A_{n}}=\delta(n)-1+\theta(n)
$$

Eq. [9] is the ratio of net income to appraised asset value, or, equivalently, the asset's rate of return at time $t$ showing that in the presence of economic obsolescence a plant's real discount rate must be $\delta(n)>1-\theta(n)$ in order for it to operate profitably. The rate of return equals the discount rate when the industry is viable (e.g., $\theta(n)=1$ ), whereas when the industry becomes obsolete, the rate of return turns negative. Thus, we have taken Hotelling's (1925) widely used model for asset replacement and built upon it by explicitly estimating external or asset obsolescence which has not been done in previous research.

\section{Example: the U.S. sugar beet industry}

The U.S. beet sugar industry is a logical one to use for determining whether the type of economic obsolescence we are examining exists. While an old industry, the present U.S. sugar beet industry has not built a new plant since 1975 and is entirely dependent upon U.S. farm policy (Brooks, Cameron, and Carter 1998, U.S. General Accounting Office 2002). Risch, Boland, and Crespi (2014) note that of the 81 sugar beet plants built in the United States from 1897 to $1975,83 \%$ were constructed before 1926. ${ }^{6}$ The last new plant was built in 1975 and 33 plants closed since then. Transforming beets into sugar is an equipment-intensive process and the specialized equipment generally cannot be used in any other industry impacting its salvage value. As there are no economically viable alternative uses for either sugar beets or sugar beet processing plants, closure means the property is totally abandoned and once closed permanently, no sugar beet plant has ever reopened. ${ }^{7}$

6 For this study, we analyzed every sugar beet plant sale in U.S. Mergers and Acquisitions over time to trace plant ownership. We have figures by year of the number of new plants built and industry capacity, which are available upon request.

7 The Delta Sugar plant in Clarksburg, California is the only plant that has been put to other uses. In this case, the exterior brick work has been used to house a winery. 
Historically, the cost of producing the cheaper cane sugar in the international market is, on average, less than half the cost of producing beet sugar but a tariff-rate quota (TRQ) restricts the U.S. supply of imported sugar (Moss and Schmitz 2002; Petrolia and Kennedy 2003). Loans are provided to sugar processors through the U.S. Department of Agriculture's Commodity Credit Corporation, with sugar pledged as collateral at a government-set price, or loan rate that varies by region. Accordingly, profitability of the beet sugar industry is contingent on a loan rate price that is equal to or greater than the TRQ price for imported sugar. Consistent with the story of economic obsolescence and higher appraisal values, since 2002, 17 sugar beet plants were sold for a fraction of their appraised value while five more could find no buyers and were closed. This can also have property tax implications. In Southern Minnesota Beet Sugar Coop v. County of Renville (2007) a county appraisal put the market value of the plant at over \$20 million. The cooperative countered that based upon sales of similar plants the estimated market value was closer to $\$ 7.5$ million. Another plant in Worland, Wyoming sold for \$1.5 million in 2002 after inventory and other current assets had been accounted for. Its most recent appraisal had been for $\$ 5.648$ million (Boland 2003). If external obsolescence can be measured, we should expect to find it in this industry.

\section{Data}

Table 1 provides the statistics for the data used in the estimation. We have data containing annual observations for each of the 26 sugar beet plants operating in the United States from 1997 to 2006. Unless otherwise noted, all data are taken from the U.S. Department of Agriculture National Agricultural Statistics Service, 2011 or U.S. Department of Agriculture, Economic Research Service, various years; Beet Sugar Development Foundation, 1982; and U.S. Department of Commerce.

\subsection{Cost and revenue data}

We first construct the annual net income, eq. [1], for each plant. Annual plant revenue, $p_{t} Y_{t}$ is plant production in pounds of refined sugar, $Y_{t}$, multiplied by the average (wholesale) dollars received per pound, $p_{t}$. All prices and costs are deflated to 2006 dollars, the last year of our data set, using the Consumer Price Index. Production of refined sugar per plant is determined by multiplying the reported annual county deliveries of sugar beets near a plant by the average percent sucrose of sugar beets per county per year. The price for refined sugar is an annual, average state-level price and is the same for each plant in a state.

Costs are broken out into known production costs, $c_{t}$ and unknown costs at each plant, $K_{t}$ so that

$$
C_{t}=c_{t}+\beta_{K} K_{t}
$$

where $\beta_{K}$ is a parameter to be estimated. The portion of cost that can be calculated directly from the plant-level data $\left(c_{t}\right)$ is the average annual dollars per ton paid by the refinery to sugar beet farmers in each state multiplied by the total tons procured by each plant in a given year.

We estimated the unknown plant-level costs in two ways, resulting in two different formulations of $K_{t}$ as a cost proxy. First, assuming costs are a function of plant size, model 1 measures $K_{t}$ as a plant's percent capacity utilization $\left(U_{t}\right)$ defined as the tons of sugar beets used by

Table 1 Statistics for data used in the analysis

\begin{tabular}{|c|c|c|}
\hline Variable $^{\mathrm{a}}$ & Mean & Std. Err \\
\hline$A_{t}$, Appraisal (\$) & $5,670,689$ & $2,977,334$ \\
\hline$C A P_{t}$, Industry capital expenditures (\$ millions) & 116.87 & 61.31 \\
\hline $\operatorname{Corn}_{t}$ (millions of harvested bushels in county of plant) & 6.96 & 8.99 \\
\hline$F_{t}$, Industry fuel costs (\$ millions) & 155.84 & 18.27 \\
\hline$M_{t}$, (lbs of U.S. sugar imports)/(lbs of plant production) & $1,218.93$ & $1,517.67$ \\
\hline$\tilde{\pi}_{t}$, Net income less estimated plant-level costs (\$) & $69,091,165$ & $56,327,238$ \\
\hline$P S_{t}$, Price of sugar (cents/lb) & 26.21 & 3.24 \\
\hline$R_{t}$, Weighted average cost of capital (\%) & 0.18 & 0.02 \\
\hline Trend $_{t}$ (year of observation) & $2,001.5$ & 2.88 \\
\hline$W_{t}$, Industry payroll avg weekly Wage ( $\$$ thousands) & 674.55 & 138.18 \\
\hline$Z$, Dependent variable (see text) & 23.15 & 77.99 \\
\hline
\end{tabular}

Note: ${ }^{\mathrm{a}}$ Number of observations is 260 . 
a plant in a year divided by the product of that plant's capacity and the number of days that plant operated in that year. In model 1 , we also include cost measures that vary over time but are constant for every plant and obtained from the U.S. Department of Commerce's Bureau of the Census Annual Survey of Manufactures for the U.S. beet-sugar refining industry. These are fuel costs $\left(F_{t}\right)$, capital expenditures $\left(\operatorname{Cap}_{t}\right)$, and average weekly wages $\left(W_{t}\right)$. In the second model, we simply proxy $K_{t}$ by a plant-level dummy variable. We leave $F_{t}$, $\mathrm{Cap}_{t}$ and $W_{t}$ out of model 2 as these variables are perfectly collinear with the fixed effects. The net income portion of eq. [9] is

$$
\pi_{t}=p_{t} Y_{t}-c_{t}-\beta_{K} K_{t}
$$

or $\pi_{t}=\tilde{\pi}_{t}-\beta_{K} K_{t}$.

\subsection{Appraisal values}

Annual appraisal values are used in the estimation of eq. [9] but we do not have one for each year because of the thinness of the sales transactions in this industry. To account for the issue, the appraisal $A_{t}$ is estimated from the appraised values we do have for each plant. Over the time period of our study, every plant in the data set had one or more appraisals performed using the costapproach with 12 of the 26 plants appraised in 2003. To impute the appraised value for every plant in every year, ordinary least squares regressions were estimated on these 26 plant-specific appraisal observations as a function of average percentage of sucrose found in the sugar beets used by that plant in the year of the appraisal, the price of raw sugar at that time, the capacity of the plant, and the percentage of the plant's capacity utilized at the time of the appraisal $\left(R^{2}\right.$ was 0.64$)$. This regression equation was then used to predict the appraised value for each plant in the other years of the data.

\subsection{Exogenous variables affecting obsolescence data}

Next we need to parameterize the components of the obsolescence function of eq. [9]. The vector $x_{t}$ is composed of exogenous factors affecting plant-level returns through the obsolescence function with an index function, $n=n\left(x_{t}\right)$ set to be linear. We include an intercept, a time trend to account for technological and other changes, and three additional exogenous variables.
Because the U.S. market for sugar exists under a tariff-rate quota (TRQ), imports of sugar to the United States change as this TRQ changes and affects economic obsolescence. We created the variable $M_{t}$ to proxy the competitiveness of each of the U.S. sugar beet plants by dividing total annual imports (pounds) of sugar into the United States by the amount of sugar processed per plant (pounds). This ratio increases as imports increase and decreases as a plant's output increases.

We also use the world price of sugar, $P S_{t}$ because the price of sugar on the world market impacts the competitiveness of sugar beet refining as it rises or falls with respect to the loan rate. ${ }^{8}$ We include the output of corn, $\mathrm{Corn}_{t}$ (millions of bushels), in the county where a factory is located. This variable is included because of the redistribution of sugar beet acres toward corn in recent years due to demand factors for corn such as its use in sweeteners, ethanol, and drought-tolerant corn varieties. Sourcing sugar beets from farther distances to a plant should be correlated with the supply of corn close to a plant. The relationship between the obsolescence measure and $M_{t}$ and $\operatorname{Corn}_{t}$ could be positive or negative. If, as these variables increase, $\theta_{t}$ goes to zero, then imported sugar and uses of corn are squeezing sugar beet plant profitability. On the other hand if the relationship is positive, it could be because increases in these variables are correlated with stronger demand for sugar in general. The relationship between obsolescence and $P S_{t}$ is expected to be positive.

\subsection{Weighted average cost of capital data}

We incorporate this external obsolescence function along with the net income and the appraised value to construct eq. [9]. The final variable remaining in eq. [9] is the discount rate. We define $\delta_{t}=\gamma R_{t}$ where $R_{t}$ is the cost of capital and $\gamma$ is a parameter to be estimated. The cost of capital $R_{t}$ was proxied by the weighted average cost of capital. For firms that report to the U.S. Securities and Exchange Commission (SEC), data were obtained from the annual 10-k which reports annual income statements, balance sheets, and cash flow statements. $R_{t}$ is represented as

8 A linear regression of $P S_{t}$ on $M_{t}$ resulted in a regression equation with an $R^{2}$ of less than 0.05 . This is because both the denominator of $M_{t}$ and the peculiarities of the TRQ make the correlation between U.S. sugar imports and the world price of sugar weaker than it would be in the absence of a TRQ. 


$$
R_{t}=W_{d t} k_{d t}\left(1-r_{t}\right)+W_{e t} k_{e t}
$$

where $W_{d t}$ is the weight of debt in the capital structure, $k_{d t}$ is the cost of debt capital, $r_{t}$ is the effective tax rate, $W_{e t}$ is the weight of equity in the capital structure, and $k_{e t}$ is the cost of equity capital. The firm's tax rate is assumed to be constant at $40 \%$ over this time period. The cost of debt or $k_{d t}$ was determined using the cost of debt for similar sized firms. The cost of equity was determined by using the Buildup Method whereby the cost of equity equals the sum of the risk-free rate, the equity risk premium, a firm size premium, and the industry risk premium (Ibbotson SBBI 2008). The risk-free rate is chosen to be the yield on a U.S. Treasury security (20 year bond) in each year which was $4.84 \%$. The equity risk premium is chosen to be the long-term equity risk premium since 1926 or $7 \%$. The firm size premium is assumed to be the micro-cap premium which is $3.5 \%$. No published industry risk premium is available. However, this industry has unique risks associated with public policy an assumed risk of $25 \% .{ }^{9}$ The resultant average $R_{t}$ was $10.6 \%$ with a standard deviation of $1 \%$.

We now have all of the components of eq. [9]. Because we need to estimate the unknown components of cost as discussed above, we rearrange this equation into the estimating equation:

$$
Z_{t}=\beta_{K} K_{t} / A_{t}+\gamma R_{t}+\theta_{t},
$$

where $Z_{t}=\tilde{\pi}_{t} / A_{t}+1$. Thus, we are maximizing expected net income from the processing of sugar beets allowing for external obsolescence in the value of its assets. Hotelling's widely used methodology shows how the current value of an asset is determined by its original asset value and the rate of depreciation. We have modified Hotelling to account for external obsolescence by carefully accounting for all fixed and variable costs over a 10 year period for every sugar beet plant in the United States. The nonlinear procedure in SAS is used to estimate eq. [13] for both methods of determining variable costs of processing.

\section{Results}

Table 2 gives estimates for the two models based on the two different cost specifications. We exclude the $K_{t}$ proxy parameters for the 26 plants for brevity but these cost proxy effects resulted in 24 out of 26 coefficients that

9 We consulted independently with senior executives of two leading firms. Both found our cost of capital approach reasonable. were statistically significant at a 2.5\% level and all 26 were positive as is suggested by the theoretical model. The adjusted $R^{2}$ is 0.99 for both models. The parameters of most interest are those in the obsolescence function itself. The results show that on average, sugar beet plants have suffered from greater obsolescence over time (e.g., the negative coefficient on the Trend $_{t}$ variable in both models) and as the world price of processed sugar decreases, sugar beet plants have likewise become more obsolete.

There is also evidence that obsolescence is correlated with our measures of corn and imported sugar as the coefficients on the variables $\operatorname{Corn}_{t}$ and $M_{t}$ are positive and statistically significantly different from zero at a $2.5 \%$ level of hypothesis. Calculating the index function, $n\left(x_{t}\right)$, at the means for the variables produced negative values in both models indicating that the optimal time to sell a sugar beet plant has already occurred, which is consistent with the general state of the present market and the fact that buyers are not seeking out new plants. With all of the parameters estimated, we now use them to estimate the degree of economic obsolescence, based on eq. [9], and compare the appraised values with our estimated market values.

Table 3 uses eqs [5] and [9] to calculate the means, standard deviations, minimum, and maximum values for all 26 plants. Because our interest is in the present worth of a sugar beet facility, we chose the most recent observation in the data set, 2006. The table provides the value for Net Income, our estimate of the appraised sales price $A_{t}$ (Appraisal), external obsolescence $\theta_{t}$ (Obsolescence), and an estimate of the true sales value of a plant taking into account economic obsolescence (Appraisal $\times$ Obsolescence).

Overall, the measure of obsolescence ranges from a low of $12 \%$ to a high of $32 \%$ with a mean of 16 (model 2) or 17 (model 1) percent and very low standard deviation $(5 \%)$. This measure of obsolescence has fallen from an average high in 1997 of around 21\% in both models. The anecdote of the Worland, Wyoming plant that sold for $26 \%$ of its appraised value is in the range of our findings. It should be noted that Taylor and Brester (2005) reported that economic rents capitalized in farmland prices due to the U.S. sugar program would result in a $32 \%$ reduction in Montana land values from policy changes, a change at the upper end of our calculation of obsolescence in the plants.

On the basis of our estimation, the results indicate that sugar beet plants are greatly overvalued by standard appraisal techniques. Using our appraisal estimate, $A_{t}$ (Appraisal), the average appraised value of these plants 
Table 2 Parameter estimates, standard errors, and hypothesis tests

\begin{tabular}{|c|c|c|c|c|}
\hline \multirow[t]{2}{*}{ Variable } & \multicolumn{2}{|c|}{$\begin{array}{r}\text { Model 1-using capacity utilization to } \\
\text { proxy unknown plant costs }\end{array}$} & \multicolumn{2}{|c|}{$\begin{array}{l}\text { Model 2-using fixed effects to } \\
\text { proxy unknown plant costs }\end{array}$} \\
\hline & Parameter & Std. Err & Parameter & Std. Err \\
\hline$R_{t}$ & -0.986 & $0.258^{\star}$ & -2.216 & $0.580^{*}$ \\
\hline$F_{t}$ & $1,735.943$ & $1,025.9^{+}$ & & \\
\hline$C A P_{t}$ & 33.762 & 262.8 & & \\
\hline$w_{t}$ & $-1,395.270$ & $799.2^{+}$ & & \\
\hline \multicolumn{5}{|c|}{ Obsolescence parameters } \\
\hline Constant & 70.667 & $27.697^{*}$ & 129.206 & $37.000 *$ \\
\hline Trend $_{t}$ & -0.037 & $0.014^{\star}$ & -0.066 & 0.019 * \\
\hline Corn $_{t}$ & 0.026 & $0.009^{*}$ & 0.022 & 0.010 \\
\hline$M_{t}$ & $5.30 \mathrm{E}-05$ & $3.20 \mathrm{E}-05^{+}$ & $1.14 \mathrm{E}-04$ & $4.90 \mathrm{E}-05^{*}$ \\
\hline$P S_{t}$ & 0.070 & $0.016^{*}$ & 0.019 & 0.014 \\
\hline Adjusted $R^{2}$ & 0.9980 & & 0.9881 & \\
\hline
\end{tabular}

Notes: Dependent variable is given in eq. [9]. Variables are as follows: $R_{t}$ is the weighted average cost of capital; $F_{t}$ is a measure of fixed cost as capacity utilization in model 1 and a fixed effect in model 2; CAP $t$ is industry capital expenditures; $W_{t}$ is industry average weekly payroll wages; Trend $_{t}$ is a trend term, $M_{t}$ is the ratio of pounds of U.S. sugar imports to pounds of plant production, and $P S_{t}$ is the price of sugar. *indicates significance at the $2.5 \%$ hypothesis level and + indicates significance at the $5 \%$ level. 26 plant-level cost effects are not shown but available from the authors. All cost effect coefficients were positive, consistent with eq. [9], and 24 out of 26 were significant at the $2.5 \%$ hypothesis level in both models.

Table 3 Net income, appraisal, obsolescence and estimated market value for 2006

\begin{tabular}{lrrrr}
\hline Variable & Mean & Std Dev & Minimum & Maximum \\
\hline Net income & $\$ 90,683,372$ & $\$ 80,299,252$ & $\$ 11,525,381$ & $\$ 270,558,686$ \\
Appraisal & $\$ 2,526,081$ & $\$ 2,230,698$ & $\$ 179,983$ & $\$ 7,834,809$ \\
Model 1 & & & & \\
Obsolescence & $17 \%$ & $5 \%$ & $13 \%$ & $32 \%$ \\
Appraisal $\times$ Obsolescence & $\$ 429,434$ & $\$ 111,535$ & $\$ 23,398$ & $\$ 2,507,139$ \\
Model 2 & & & & $32 \%$ \\
Obsolescence & $16 \%$ & $5 \%$ & $12 \%$ & $\$ 2,507,139$ \\
Appraisal $\times$ Obsolescence & $\$ 404,173$ & $\$ 111,535$ & $\$ 21,598$ & $\$$
\end{tabular}

Notes: Statistics based on values and estimates using data for all 26 plants in 2006, the last year of the sample.

in 2006 ranges from a low of $\$ 0.179$ million to a high of $\$ 7.8$ million with an average value of $\$ 2.5$ million. Our models' average estimates of a plant's actual worth in 2006 are (Appraisal $\times$ Obsolescence) $\$ 0.429$ million in model 1 and $\$ 0.404$ million in model 2 with a minimum value of $\$ 0.022$ million and a maximum of $\$ 2.5$ million. Using model 1, for example, we find that the world price of sugar would need to rise to nearly $\$ 1$ a pound in order for the appraised value to be consistent with a plant's actual worth when taking the economic obsolescence into account. In real terms, a \$1 per pound price would correspond roughly with world sugar prices from the late 1970s and early 1980s, exactly the time marking the beginning of the industry's decline. Our conclusion is that in 2006, these plants were greatly overvalued because the appraisal does not factor in the obsolescence in the industry.

\section{Conclusion}

Appraising a firm's assets in the presence of potential external obsolescence where capital may become stranded is made more difficult if the assets in the industry are sold only sporadically or the economic impacts are uncertain. No previous research has been undertaken to examine the capitalization of this type of economic obsolescence and how these measures compare with 
appraised values, especially in industries where market transactions are few, assets have no alternative use, and government policy impacts asset value. Such external impacts are common in food and agricultural industries and understanding their impacts on asset valuation is important because of the well-known link between sunk costs and industry structure (Sutton 1996).

In this paper, we developed a technique based on Hotelling's (1925) much-used depreciation methodology to parameterize the impacts of external obsolescence based upon an asset's net returns, appraised values, economic factors that impact the demand for a good in the industry, and the economic theory of the optimal time of asset sale. We applied our technique to assets of the U. S. sugar beet industry, an industry whose present existence is due almost solely to government policy and for whom assets have no alternative uses. Our findings are consistent with the evidence in the industry that appraised values are not capturing the actual value of plant and equipment. Further they show that a change in demand due to government policy making the price of $U$. S. sugar beets less competitive relative to other forms of sugar explains why the value of sugar beet plants declined so much over the time period under study. Our estimates of asset obsolescence between 12 and 32\% mean that plant appraisals using currently accepted practices greatly overstate the true value of these assets. The fact that sugar beet facilities today are left idle rather than sold at prices near their appraised values is likewise consistent with our findings. To put this in the context of the industrial structure, as researchers examine the relationship between market concentration and sunk costs in food and agricultural markets, the measurement of the asset variable becomes problematic for those industries operating under great uncertainty due to government policies. Future research should apply these techniques to stranded capital questions in natural resources as well as compare and contrast other industries as data become available.

\section{References}

Barnard, C. H., G. Whittaker, D. Westenbarger, and M. Ahearn. 1997. "Evidence of Capitalization of Direct Government Payments into U.S. Cropland Values." American Journal of Agricultural Economics 79:1642-50.

Beet Sugar Development Foundation. 1982. Beet-Sugar Technology, 3rd ed. Fort Collins, CO: Studio of Printcraft.

Boland, M. 2003. "Wyoming Sugar Company LLC." Arthur Capper Cooperative Center Case Study Series 03-02. Presented at Sixth
Annual Farmer Cooperatives Conference, Kansas City, MO, October 30-31.

Brooks, J. C., A. C. Cameron, and C. A. Carter. 1998. "Political Action Committee Contributions and U.S. Congressional Voting on Sugar Legislation." American Journal of Agricultural Economics 80(3):441-54.

Burt, O. R. 1972. "A Unified Theory of Depreciation.” Journal of Accounting Research 10(1):28-57.

Fare, R., S. Grosskopf, and C. A. K. Lovell. 1985. The Measurement of Efficiency of Production. Boston, MA: Kluwer-Nijhoff.

Featherstone, A. M., and T. G. Baker. 1988. "Effects of Reduced Price and Income Supports on Farmland Rent and Value." North Central Journal of Agricultural Economics 10:177-89.

Fisher, J. D., G. H. Lentz, and J. J. Stern. 1984. "Tax Incentives for Investment in Nonresidential Real Estate." National Tax Journal 6:9-87.

Fisher, F. M., and J. J. McGowan. 1983. "On the Misuse of Accounting Rates of Return to Infer Monopoly Profits." American Economic Review 73:82-97.

Hilber, C. A. L., and C. Mayer. 2009. "Why Do Households Without Children Support Local Public Schools? Linking House Price Capitalization to School Spending." Journal of Urban Economics 65:74-90.

Hilber, C. A. L., and T. Turner. "The Mortgage Interest Deduction and Its Impact on Homeownership Decisions." The Review of Economics and Statistics. Posted Online November 12, 2013. doi:10.1162/REST_a_00427.

Hotelling, H. 1925. "A General Mathematical Theory of Depreciation." Journal of American Statistical Association 20:340-53.

Ibbotson SBBI. 2008. 2008 Classic Yearbook: Market Results for Stocks, Bonds, Bills, and Inflation, 1926-2007. Chicago, IL: Morningstar, Inc.

Jackson, T. O. 2001. "The Effects of Environmental Contamination on Real Estate: A Literature Review.” Journal of Real Estate Literature 9:93-116.

Kirwan, B. E. 2009. "The Incidence of U.S. Agricultural Subsidies on Farmland Rental Rates." Journal of Political Economy 117:13864.

Kolbe, A. L., and L. S. Borucki. 1998. "The Impact of Stranded-Cost Risk on Required Rates of Return for Electric Utilities: Theory and an Example." Journal of Regulatory Economics 13:255-75.

Moschini, G., and D. Hennessy. 2001. "Uncertainty, Risk Aversion, and Risk Management for Agricultural Producers." In Handbook of Agricultural Economics. Volume 1a. Agricultural Production, edited by B. L.Gardner and G. C. Rausser, 87-153. NorthHolland, Amsterdam: Elsevier Science.

Moss, C. B., and A. Schmitz. 2002. "Vertical Integration and Trade Policy: The Case of Sugar." Agribusiness: An International Journal 18:49-60.

National Agricultural and Statistics Service, US Department of Agriculture. 2011. Accessed November. http://www.nass.usda. gov/Data_and_Statistics/Quick_Stats/.

Netzell, 0. 2009. "A Study of Micro-Level Variation in AppraisalBased Capitalization Rates." Journal of Property Research 26:235-63.

Nourse, H. 0. 1987. “The 'Cap Rate,' 1966-1984: A Test of the Impact of Income Tax Changes on Income Property." Land Economics 63:147-52.

Oates, W. E. 1969. "The Effect of Property Taxes and Local Public Spending on Property Values: An Empirical Study of Tax 
Capitalization and the Tiebout Hypothesis." Journal of Political Economy 77:957-71.

Perrin, R. K. 1972. “Asset Replacement Principles.” American Journal of Agricultural Economics 54(1):60-67.

Petrolia, D. R., and P. L. Kennedy. 2003. "Increasing the U.S. TariffRate Sugar Quota for Cuba and Mexico: A Partial-Equilibrium Simulation." Journal of Agricultural and Applied Economics 35 (3):589-97.

Risch, C. C., M. A. Boland, and J. M. Crespi. 2014. "Survival of U.S. Sugar Beet Plants from 1897 to 2011." Agribusiness 30:1-13.

Schulz, L. L., and J. M. Crespi. 2012. "Presence of Check-Off Programs and Industry Concentration in the Food Manufacturing Sector." Agribusiness 28:148-56.

Southern Minnesota Beet Sugar Coop, Relator, vs. County of Renville, Respondent. 2007. A07-394, Supreme Court, August 23.

Stevenson, S., J. Young, and C. Gurdgiev. 2010. “A Comparison of the Appraisal Process for Auction and Private Treaty Residential Sales." Journal of Housing Economics 19: 157-66.

Sutton, J. 1996. Sunk Costs and Market Structure. Cambridge, MA: MIT Press.
Taylor, M., and G. Brester. 2005. "Non-Cash Income Transfer and Land Values." Review of Agricultural Economics 27:526-41.

Troxel, C. E. 1936. "Economic Influences of Obsolescence." American Economic Review 26:280-90.

Tyrvainen, L., and A. Miettinen. 2000. "Property Prices and Urban Forest Amenities." Journal of Environmental Economics and. Management 39:205-23.

U.S. Department of Agriculture, Economic Research Service. various years. Sugar and Sweeteners Report. Washington, DC.

U.S. Department of Commerce, 1996 to 2007. "Annual Census of Manufacturers."

U.S. Environmental Protection Agency (EPA). November 2011. "Potential Stranded Capital Analysis on EPA Light-Duty Technology Cost Analysis.” EPA-420-R-11-019. Washington, DC.

U.S. General Accounting Office. 2002. "Supporting Sugar Prices Has Increased Users' Costs While Benefiting Producers." Report to Congressional Requesters, GAO/RCED-00-126.

U.S. Securities and Exchange Commission, 1996-2007. "10-K Reports, Assorted Firms."

Wilen, J. E. 2009. "Stranded Capital in Fisheries: The Pacific Coast Groundfish/Whiting Case." Marine Resource Economics 24:1-18. 